\title{
DESENVOLVIMENTO DE CAFEEIROS ENXERTADOS 'APOATÃ IAC 2258' CULTIVADOS EM RECIPIENTE DE 250 LITROS $^{(1)}$
}

\author{
Development of coffee trees (Coffea arabica $L$. L.) grafted in 'Apoatã IAC 2258' \\ grown in recipient of 250 liters $^{(1)}$
}

\author{
Fábio Pereira Dias², Antônio Nazareno Guimarães Mendes ${ }^{3}$, Haroldo Silva Vallone², \\ Alex Mendonça de Carvalho ${ }^{4}$, Samuel Pereira de Carvalho ${ }^{3}$
}

\begin{abstract}
RESUMO
Visando obter informações sobre o desenvolvimento de duas cultivares de cafeeiros Coffea arabica L. enxertados ou não em Coffea canephora Pierre, cultivar 'APOATÃ IAC 2258' foi instalado e conduzido esse ensaio, de janeiro de 2004 a maio de 2005. O delineamento experimental utilizado foi em blocos casualizados em esquema fatorial $(2 \times 3)+2$, com parcelas subdivididas no tempo e quatro repetições, sendo duas cultivares de Coffea arabica L., três tipos de mudas (enxertada, auto enxertada e pé franco), duas testemunhas do porta-enxerto Apoatã pé franco e auto enxertado e quatro épocas. Foram avaliadas altura de plantas, número de ramos plagiotrópicos, número de nós nos ramos plagiotrópicos, massa seca da parte aérea e massa seca do sistema radicular. Os resultados mostraram que a muda enxertada não é superior à muda de pé franco para nenhuma característica avaliada, independentemente da cultivar. Não foi observado efeito do estresse causado pela enxertia, mais sim efeito do porta enxerto Apoatã, para todas as características. As plantas de Apoatã apresentam maior acúmulo de massa seca de raiz que as plantas de $C$. arabica L.. Não se recomenda a utilização de mudas enxertadas para áreas isentas de nematóides.
\end{abstract}

Termos para indexação: Café, enxertia, crescimento vegetativo, raiz, nematóide.

\section{ABSTRACT}

This study was carried out during the period from January 2004 until May 2005, aimed to obtain information on the development of coffee trees grafted in 'APOATÃ IAC 2258' and ungrafted coffee trees. The experimental design used was a randomized block with a $(2 \times 3)+2$ factorial split-plot arrangement and four replications, as follows: two $C$. arabica L. cultivars, three types of seedling (grafted, self-grafted and ungrafted), two Apoatã rootstock control, ungrafted and self-grafted evaluated in four period of time. The experiments were evaluated for plant height, aerial parts dry matter, root system dry matter, plagiotropic shoots number and plagiotropic shoots nodes number. The results obtained let verify that grafted seedling was not superior to the ungrafted one for all the evaluated characteristics, regardless of the cultivar. No stress effect caused by grafting was observed, but Apoatã rootstock effect was observed for all features. Apoatã plants have more root system dry matter than C. arabica L. plants. The use of grafted seedling is not recommended for nematoid-free areas.

Index terms: Coffee, Grafting, Vegetative growth, Root, Nematoid.

(Recebido em 3 de abril de 2006 e aprovado em 22 de dezembro de 2006)

\section{INTRODUÇÃO}

Atualmente, a enxertia é a técnica mais promissora para se conviver com os fitonematóides, destacando o porta-enxerto 'APOATÃ IAC 2258', de C. canephora Pierre, que é resistente, mas não imune a Meloidogyne incognita e Meloidogyne exigua (FAZUOLI et al., 1987). Além da resistência de determinados porta-enxertos aos fitonematóides, alguns autores destacam um maior desenvolvimento do sistema radicular e da parte aérea e uma maior eficiência na absorção de nutrientes da solução do solo, em relação às plantas não enxertadas, podendo essas plantas ser utilizadas em áreas isentas de nematóides, aumentando com isso o potencial de produção da lavoura.

Objetivou-se com o trabalho realizado por Fahl et al. (1998), avaliar, em condições de campo isento de nematóides, o efeito da enxertia de cultivares de $C$. arabica L., sobre progênies de $C$. canephora Pierre e $C$. congensis Frochner, verificando-se que a utilização de progênies de C. canephora Pierre e $C$. congensis Frochner, como portaenxertos, conferiu maior desenvolvimento da parte aérea às cultivares de C. arabica L., sobretudo à 'Catuaí'.

\footnotetext{
${ }^{1}$ Artigo extraído da Tese de Doutorado apresentada à Universidade Federal de Lavras/UFLA, pelo primeiro autor - Cx. P. 3037 - $37200-000$ - Lavras, MG ${ }^{2}$ Doutor - Departamento de Agricultura - Centro Federal de Educação Tecnológica de Bambuí/CEFET - Cx. P. 05 - $38900-000$ - Bambuí, MG dfabio@cefetbambui.edu.br, haroldo@cefetbambui.edu.br

${ }^{3}$ Doutores, Professores Adjunto - Departamento de Agricultura/DAG - Universidade Federal de Lavras/UFLA - Cx. P. 3037 - $37200-000$ - Lavras, MG nazareno@ufla.br, samuelpc@ufla.br

${ }^{4}$ Graduando - Departamento de Agricultura/DAG - Universidade Federal de Lavras/UFLA - Cx. P. 3037 - $37200-000$ - Lavras, MG carvalho.am@hotmail.com
} 
Guimarães et al. (2003) e Oliveira (2003), estudando mudas de cafeeiro, observaram maior desenvolvimento vegetativo da parte aérea das mudas de pé franco do que quando enxertadas em 'APOAT $\tilde{A}$ IAC 2258', independentemente da cultivar de $C$. arabica L., utilizada como enxerto.

Carvalho \& Costa (1977), avaliando a influência do cafeeiro $C$. canephora Pierre cultivar Guarini, como porta-enxerto das cultivares de $C$. arabica L. Laurina e 'Mundo Novo', concluíram que, para algumas características, como produção de grãos de quatro anos, altura de plantas e diâmetro de copa, não foram observadas diferenças significativas das plantas enxertadas quando comparadas com as de pé franco. Resultados semelhantes foram encontrados também por Ferrari et al. (2003) e Tomaz et al. (2005), observando que o desenvolvimento das plantas enxertadas é semelhante aos das plantas de pé franco.

Diante do exposto, objetivou-se neste trabalho avaliar o desenvolvimento de cafeeiros (C. arabica L.), enxertados em 'APOATÃ IAC 2258' (C. canephora Pierre), cultivados em recipiente de 250 litros, utilizando solo corrigido e isento de nematóides.

\section{MATERIAL E MÉTODOS}

O experimento foi instalado e conduzido no viveiro de produção de mudas do Setor de Cafeicultura, do Departamento de Agricultura da UFLA, no período de janeiro de 2004 a maio de 2005. O delineamento experimental utilizado foi em blocos casualizados (DBC), em esquema fatorial $(2 \times 3)+2$, com parcelas subdivididas no tempo e quatro repetições. Foram utilizados: a) duas cultivares de C. arabica L.: Catucaí Amarelo 2SL e Topázio MG 1190; b) três tipos de mudas: enxertada, auto-enxertada e pé franco e, c) duas testemunhas do porta-enxerto 'APOATÃ IAC 2258' auto-enxertado e pé franco. No total foram utilizados oito tratamentos e 32 parcelas. As enxertias e as autoenxertias foram realizadas quando as plântulas do portaenxerto e das cultivares de $C$. arabica L. atingiram o estádio de "palito de fósforo", segundo metodologia proposta por Souza et al. (2002). Cada parcela foi constituída por duas estruturas suspensas divididas em células individualizadas, confeccionadas com bambu, amarradas com arame liso e forradas internamente com lona plástica nas laterais, medindo $100 \mathrm{~cm}$ de altura, $50 \mathrm{~cm}$ de comprimento e $50 \mathrm{~cm}$ de largura (Figura 1). Foram colocados aproximadamente 250 litros de solo corrigido (Tabela 1) e isento de nematóides, em cada uma das células, nas quais foram plantadas uma muda com três pares de folhas, em janeiro de 2004.

A interpretação da análise de solo e as adubações de plantio, cobertura e foliares seguiram a recomendação da CFSEMG (1999). As características avaliadas foram: altura da planta (ALT) medida em centímetros, do colo até o meristema apical do ramo ortotrópico; número de ramos plagiotrópicos (NRP); número de nós nos ramos plagiotrópicos (NNP); massa seca do sistema radicular (MSR), massa seca da parte aérea (MPA), em gramas por

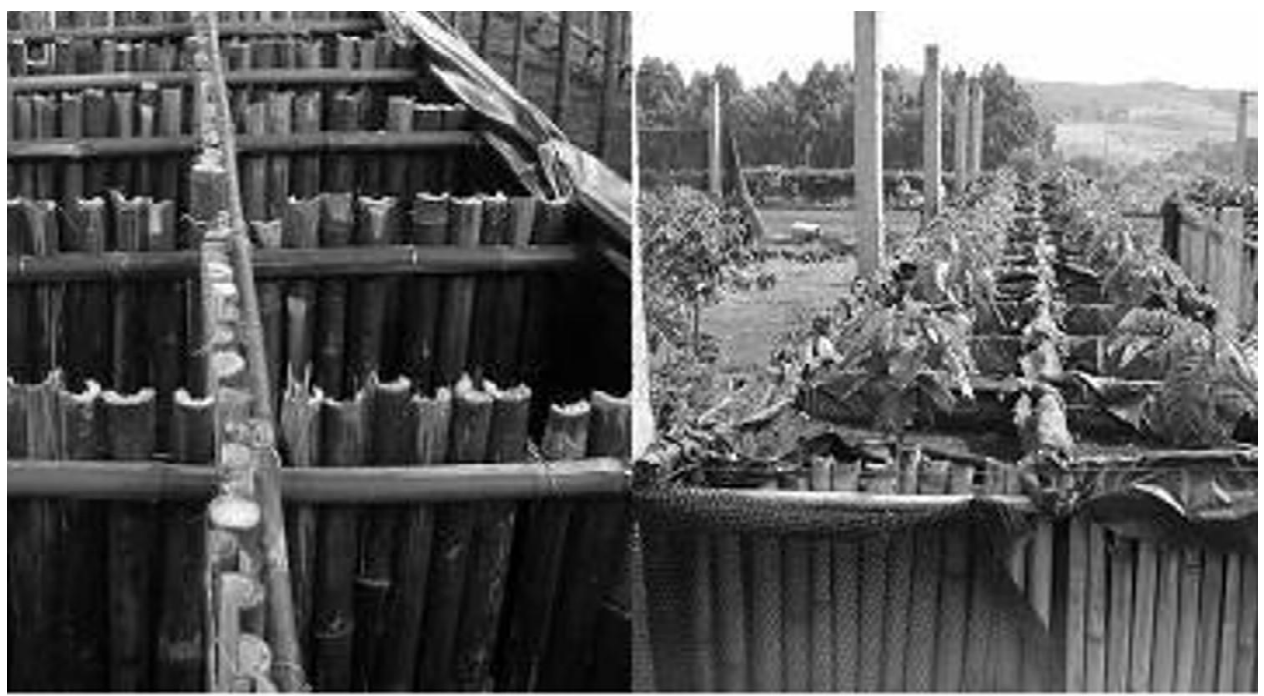

Figura 1 - Estruturas suspensas de bambu, simulando vasos para cultivo das plantas. UFLA, Lavras, MG, 2006. 
planta e relação entre a massa seca da parte aérea e a massa seca do sistema radicular (MPA/MSR). As características altura de planta, número de ramos plagiotrópicos e número de nós nos ramos plagiotrópicos foram avaliadas segundo um fatorial ( 2 x 3), em esquema de parcelas subdivididas no tempo, avaliadas em 4 épocas (maio/2004, setembro/2004, janeiro/2005 e maio/2005). As características massa seca do sistema radicular e da parte aérea foram avaliadas ao final do experimento e analisadas como um fatorial $2 \times 3$. A comparação da massa seca do sistema radicular das testemunhas entre si e com os outros 6 tratamentos foi analisada segundo um delineamento em blocos ao acaso.

As análises estatísticas foram feitas utilizando-se o programa computacional 'Sisvar', desenvolvido por Ferreira (2000). Quando diferenças significativas foram detectadas, as médias foram agrupadas entre si, pelo teste de Scott-Knott, a 5\% de probabilidade.

\section{RESULTADOS E DISCUSSÃO}

\section{Altura de planta $(\mathrm{cm})$ e massa seca da parte aérea $(\mathrm{g})$}

Houve diferenças apenas para tipos de muda. Os valores médios de altura de planta, e massa seca da parte aérea (MPA), independentemente da cultivar, são apresentados na Tabela 2.

A muda enxertada apresentou menor altura de planta e menor massa seca da parte aérea que os demais tipos de mudas, independentemente da cultivar, indicando que, nessa fase e nesse ambiente de cultivo não é o processo da enxertia (estresse) que limita o desenvolvimento da planta e sim a presença do portaenxerto Apoatã na combinação.

Oliveira (2003) verificou, em plantas cultivadas em vaso, que, independentemente da cultivar, a muda enxertada desenvolveu-se menos que a muda de pé franco. Este autor comenta que, nesta fase, as plantas ainda não se recuperaram do estresse causado pela enxertia. Contudo, Garcia et al. (2005) e Tomaz et al. (2005) avaliando linhagens de $C$. arabica $\mathrm{L}$. cultivadas em vaso, não observaram diferenças para altura das plantas enxertadas ou não em clones de C. canephora Pierre. No entanto, esses autores não avaliaram o efeito causado pelo processo da enxertia, não podendo concluir se o menor desenvolvimento das plantas enxertadas foi em função do estresse causado pela enxertia, ou algum tipo de incompatibilidade entre o enxerto e o porta-enxerto.

Sugere-se com os resultados desse trabalho que a existência de algum tipo de incompatibilidade entre o portaenxerto 'Apoatã' e as copas de $C$. arabica L. Esta incompatibilidade pode ser anatômica (estrutural), em função de diferenças anatômicas entre as duas espécies, dificultando o ajuste entre os tecidos; nutricional, em função de que uma espécie pode apresentar um padrão de absorção de água e nutrientes em quantidade e composição que não seja adequado à outra espécie; ou bioquímica, devido à presença de alguma substância em uma das espécies, que interfira no comportamento da outra.

Tabela 1 - Resultado da análise de solo utilizado para cultivo nas estruturas suspensas. UFLA, Lavras, MG, 2006.

\begin{tabular}{|c|c|c|c|c|c|c|c|c|c|c|c|}
\hline $\mathrm{pH}$ & $\mathrm{K}$ & $\mathrm{Ca}^{2+}$ & $\mathrm{Mg}^{2+}$ & $\mathrm{Al}^{3+}$ & $\mathrm{H}+\mathrm{Al}$ & SB & $(\mathrm{t})$ & $(\mathrm{T})$ & $\mathrm{V}$ & $\mathrm{m}$ & P-rem \\
\hline $\mathrm{H}_{2} \mathrm{O}$ & $\mathrm{mg} / \mathrm{dm}^{3}$ & & & & $\mathrm{~mol}_{\mathrm{c}} / \mathrm{dm}^{3}$ & & & & & & $\mathrm{mg} / \mathrm{L}$ \\
\hline 6,2 & 41,3 & 4,1 & 1,1 & 0 & 3,6 & 5,9 & 5,9 & 9,5 & 62 & 0 & 14,7 \\
\hline
\end{tabular}

Tabela 2 - Altura de plantas e massa seca da parte aérea (MPA) de duas cultivares de cafeeiros, propagados por três tipos de muda em quatro épocas de avaliação. UFLA, Lavras, MG, 2006.

\begin{tabular}{lcc}
\hline Tipos de muda & Altura de Planta $(\mathrm{cm})$ & MPA $(\mathrm{g})$ \\
\hline Enxertada & $56,66 \mathrm{~b}$ & $511,7 \mathrm{~b}$ \\
Auto-enxertada & $59,05 \mathrm{a}$ & $599,6 \mathrm{a}$ \\
Pé Franco & $58,59 \mathrm{a}$ & $620,2 \mathrm{a}$ \\
CV $(\%)$ & 6,38 & 9,50 \\
Média & 58,20 & 577,21 \\
\hline
\end{tabular}

Médias seguidas de mesma letra na vertical não diferem entre si, pelo teste de Scott-Knott, a 5\% de probabilidade. 
Número de ramos plagiotrópicos e número de nós nos ramos plagiotrópicos

Observa-se que houve efeito significativo nas três ultimas épocas avaliadas, tendo a muda enxertada menores valores para essa característica que as demais (Tabela 3).

As plantas de pé franco e as auto-enxertadas apresentaram, em média, maior número de ramos plagiotrópicos, quando comparadas com a muda enxertada, não sendo observado efeito do estresse causado pela enxertia. Esses resultados concordam com os observados por Figueiredo Júnior (1999) e Oliveira (2003), em que as plantas enxertadas desenvolveram menos do que as de pé franco. Figueiredo Júnior (1999) associa esse menor desenvolvimento das plantas enxertadas ao efeito do estresse causado pela enxertia, mas avaliando os resultados desse experimento, observa-se que a muda autoenxertada foi semelhante à muda de pé franco.

Tomaz et al. (2005) não encontraram diferenças para número de ramos plagiotrópicos entre as plantas de $C$. arabica L., enxertadas ou não nos clones de $C$. canephora Pierre, quando cultivadas em vaso.

Para a característica número de nós nos ramos plagiotrópicos houve efeito significativo apenas nas duas últimas épocas avaliadas (janeiro e maio de 2005), tendo a muda enxertada apresentado menores valores que as demais (Tabela 3).

Tomaz et al. (2005) não encontraram diferenças para o número de nós nos ramos plagiotrópicos, entre as plantas enxertadas ou não, para a grande maioria dos clones testados. Já Oliveira (2003) verificou que as mudas pé franco são superiores às mudas enxertadas, resultado semelhante aos obtidos neste trabalho.

Para as características massa seca do sistema radicular, massa seca da parte aérea e relação parte aérea/ sistema radicular não houve interação entre os fatores estudados, e também não foram observadas diferenças significativas entre os tratamentos para a massa seca do sistema radicular. Esses resultados não coincidem com os encontrados por Oliveira (2003), nos quais, na fase de mudas, não se observaram diferenças entre os tipos de muda e, quando avaliadas em vasos, as plantas enxertadas produziram menos massa do sistema radicular que as de pé franco. Entretanto, ressalta-se que o período de condução do presente trabalho foi maior que o período de avaliação utilizado por Oliveira (2003), podendo proporcionar resultados mais consistentes.

Observaram-se diferenças para massa seca do sistema radicular entre os tratamentos analisados, conforme a Tabela 4.

Todos os tratamentos de $C$. arabica L., enxertados ou não no porta-enxerto 'Apoatã' e auto-enxertados, apresentaram menor massa seca do sistema radicular, quando comparados com as plantas do porta-enxerto Apoatã auto-enxertadas e pé franco. De forma geral, os tratamentos enxertados e auto-enxertados produziram 55\% menos massa seca do sistema radicular que as plantas pé

Tabela 3 - Número de ramos plagiotrópicos e número de nós nos ramos plagiotrópicos de plantas de duas cultivares de cafeeiros, propagadas por três tipos de mudas, em quatro épocas de avaliação. UFLA, Lavras, MG, 2006.

\begin{tabular}{|c|c|c|c|c|c|}
\hline \multicolumn{6}{|c|}{ Número de ramos plagiotrópicos } \\
\hline \multirow[t]{2}{*}{ Tipos de Muda } & \multicolumn{5}{|c|}{ Épocas de avaliação } \\
\hline & $\begin{array}{l}\text { Maio/ } \\
2004\end{array}$ & $\begin{array}{c}\text { Setembro/ } \\
2004\end{array}$ & $\begin{array}{c}\text { Janeiro/ } \\
2005\end{array}$ & $\begin{array}{l}\text { Maio/ } \\
2005\end{array}$ & Média \\
\hline Enxertada & $5,06 \mathrm{a}$ & $12,37 \mathrm{~b}$ & $21,93 \mathrm{~b}$ & $34,56 \mathrm{~b}$ & $18,48 \mathrm{~b}$ \\
\hline Auto-enxertada & $5,68 \mathrm{a}$ & $13,75 \mathrm{a}$ & $24,25 \mathrm{a}$ & $36,62 \mathrm{a}$ & $20,07 \mathrm{a}$ \\
\hline Pé franco & $5,75 \mathrm{a}$ & $13,12 \mathrm{a}$ & $24,06 \mathrm{a}$ & $37,18 \mathrm{a}$ & $20,03 \mathrm{a}$ \\
\hline $\mathrm{CV}(\%)$ & & & 3,98 & & \\
\hline \multicolumn{6}{|c|}{ s ramos plagiotrópicos } \\
\hline \multirow[t]{2}{*}{ Tipos de Muda } & \multicolumn{5}{|c|}{ Épocas de avaliação } \\
\hline & $\begin{array}{l}\text { Maio/ } \\
2004\end{array}$ & $\begin{array}{c}\text { Setembro/ } \\
2004\end{array}$ & $\begin{array}{c}\text { Janeiro/ } \\
2005\end{array}$ & $\begin{array}{l}\text { Maio/ } \\
2005\end{array}$ & Média \\
\hline Enxertada & 8,75 a & $46,25 \mathrm{a}$ & $153,50 \mathrm{~b}$ & $359,75 \mathrm{~b}$ & $142,06 \mathrm{~b}$ \\
\hline Auto-enxertada & $11,31 \mathrm{a}$ & $57,31 \mathrm{a}$ & $179,18 \mathrm{a}$ & 406,37 a & $163,54 \mathrm{a}$ \\
\hline Pé franco & $12,00 \mathrm{a}$ & $55,56 \mathrm{a}$ & $181,00 \mathrm{a}$ & $413,75 \mathrm{a}$ & $165,57 \mathrm{a}$ \\
\hline $\mathrm{CV}(\%)$ & & & 6,55 & & \\
\hline
\end{tabular}

Médias seguidas de mesma letra na vertical não diferem entre si, pelo teste de Scott-Knott, a 5\% de probabilidade. 
Tabela 4 - Matéria seca do sistema radicular de plantas em duas cultivares de cafeeiros, propagadas por três tipos de mudas. UFLA, Lavras, MG, 2006.

\begin{tabular}{lllr}
\hline \multicolumn{1}{c}{ Cultivares } & Tipos de muda & MSR (g) & $\%$ \\
\hline Catucaí Amarelo 2SL & Enxertada & $229,91 \mathrm{~b}$ & 56,4 \\
Topázio MG 1190 & Enxertada & $223,04 \mathrm{~b}$ & 55,0 \\
Catucaí Amarelo 2SL & Auto-enxertada & $215,84 \mathrm{~b}$ & 53,0 \\
Topázio MG 1190 & Auto-enxertada & $226,78 \mathrm{~b}$ & 55,6 \\
'APOATÃ IAC 2258' & Auto-enxertada & $387,07 \mathrm{a}$ & 95,0 \\
Catucaí Amarelo 2SL & Pé franco & $248,52 \mathrm{~b}$ & 61,0 \\
Topázio MG 1190 & Pé franco & $199,51 \mathrm{~b}$ & 48,9 \\
'APOATÃ IAC 2258' & Pé franco & $407,61 \mathrm{a}$ & 100,0 \\
\hline \multicolumn{1}{c}{ CV(\%) } & & 19,15 & \\
\hline
\end{tabular}

Médias seguidas de mesma letra na vertical não diferem entre si, pelo teste de Scott-Knott, a 5\% de probabilidade.

franco de Apoatã, evidenciando que este porta-enxerto, quando enxertado nas plantas de $C$. arabica L., não produz mais massa seca de raiz.

Ramos \& Lima (1980), avaliando o desenvolvimento de plantas de $C$. arabica L. e C. canephora Pierre, cultivadas em vasos, aos 22 meses de idade, encontraram que a cultivar Guarini (C. canephora Pierre) apresentou maior crescimento das raízes e da parte aérea, e esse resultado também foi observado em plantas mais jovens (mudas).

Rena (1998), citado por Rena \& Guimarães (2000), estudando vários sistemas radiculares de café 'Conillon', em Linhares, ES, não encontrou diferenças para o sistema radicular das plantas de $C$. arabica L., quanto à sua estrutura e distribuição.

No entanto, os resultados do presente trabalho (Tabela 4) evidenciam que as plantas de $C$. canephora Pierre apresentam um sistema radicular mais desenvolvido. Contudo essa característica não é mantida quando essas plantas são utilizadas como porta-enxerto, não justificando a utilização do porta-enxerto 'APOATÃ IAC 2258', em áreas isentas de nematóides. As plantas auto-enxertadas das duas cultivares desenvolveram-se de forma semelhante às plantas de pé franco, indicando que o efeito da enxertia (estresse) também já não é observado para essa característica. O problema pode estar na incompatibilidade entre as duas espécies, já citada anteriormente neste trabalho.

\section{CONCLUSÕES}

Considerando as duas cultivares, o ambiente de cultivo conclui-se que:
Em área isenta de nematóides, a enxertia sobre 'APOATÃ IAC 2258' não se justifica;

A muda enxertada não apresenta maior desenvolvimento que a muda de pé franco;

A cultivar 'APOATÃ IAC 2258' apresenta maior massa seca do sistema que as plantas de $C$. arabica L..

\section{REFERÊNCIAS BIBLIOGRÁFICAS}

CARVAlhO, A.; COSTA, W. M. da. Comparação de características de algumas cultivares de café enxertadas e de pé franco. In: CONGRESSO BRASILEIRO DE PESQUISAS CAFEEIRAS, 5., 1977, Guarapari. Resumos... Rio de Janeiro: MIC/IBC, 1977. p. 77.

COMISSÃO DE FERTILIDADE DO SOLO DO ESTADO DE MINAS GERAIS. Café. In: _. Recomendação para
o uso de corretivos e fertilizantes em Minas Gerais: $5^{\text {a }}$ aproximação. Viçosa, 1999. p. 289-302.

FAHL, J. I.; CARRELI, M. L. C.; GALLO, P. B.; COSTA, W. M. da; NOVO, M. do C. de S. S. Enxertia de Coffea arabica L. sobre progênies de Coffea canephora Pierre e de $C$. congensis Frochner no crescimento, nutrição mineral e produção. Bragantia, Campinas, v. 57, n. 2, p. 297-312, 1998.

FAZUOLI, L. C.; LIMA, M. M. A. de; GONÇALVES, W.; COSTA, W. M. da. Melhoramento do cafeeiro visando resistência a nematóides: utilização de porta-enxertos resistentes. In: CONGRESSO PAULISTA DE AGRONOMIA, 6., 1987, Piracicaba. Anais... São Paulo: AEASP, 1987. p. 171-180. 
FERRARI, R. B.; SAKIYAMA, N. S.; TOMAZ, M. A.; MATTA, F. M. da; MARTINEZ, H. E. P.; ZAMBOLIM, L.; ALVES, A. P. Crescimento de cafeeiros enxertados, avaliados na fase de implantação no campo. In: SIMPÓSIO DE PESQUISA DOS CAFÉS DO BRASIL, 3., 2003, Porto Seguro. Resumos... Brasília, DF: Embrapa-CAFÉ, 2003. p. 283.

FERREIRA, D. F. Análises estatísticas por meio do Sisvar para Windows versão 4.0. In: REUNIÃO ANUAL DA REGIÃO BRASILEIRA DA SOCIEDADE INTERNACIONAL DE BIOMETRIA, 45., 2000, São Carlos. Anais... São Carlos: UFSCar, 2000. p. 255-258.

FIGUEIREDO JUNIOR, W. P. Plantio de mudas de cafeeiro nas entrelinhas da lavoura adulta. 1999. 44 p. Dissertação (Mestrado em Fitotecnia) - Universidade Federal de Lavras, Lavras, 1999.

GARCIA, A. W. R.; JAPIASSÚ, L. B.; FROTA, G. B. Avaliação do efeito da enxertia na produção do cafeeiro em diferentes cultivares plantados em solo sem nematóides: dados preliminares: $3^{\mathrm{a}}$ colheita. In: CONGRESSO BRASILEIRO DE PESQUISAS CAFEEIRAS, 30., 2004, São Lourenço. Resumos... Rio de Janeiro: MIC/IBC, 2004. p. 11-12.

GUIMARÃES, R. S.; OLIVEIRA, A. L.; GUIMARÃES, R. J.; SOUZA, C. A. S.; CARVALHO, S. J. de. Efeito da enxertia no desenvolvimento de mudas de cafeeiro. In: CONGRESSO BRASILEIRO DE PESQUISAS CAFEEIRAS, 29., 2003, Araxá. Resumos... Rio de Janeiro: MIC/IBC, 2003. p. 346.

OLIVEIRA, A. L. de. Desenvolvimento de cafeeiros (Coffea arabica $L$.) enxertados submetidos a diferentes níveis de reposição de água. 2003. 56 p. Dissertação (Mestrado) Universidade Federal de Lavras, Lavras, 2003.

RAMOS, L. C. S.; LIMA, M. M. A. Avaliação da superfície relativa do sistema radicular de cafeeiros. Bragantia, Campinas, v. 39, n. 1, p. 1-5, 1980.

RENA, A. B.; GUIMARÃES, P. T. G. Sistema radicular do cafeeiro: estrutura, distribuição, atividades e fatores que o influenciam. Belo Horizonte: Epamig, 2000. 80 p. (Série documentos, 37).

SOUZA, C. A. S.; OLIVEIRA, A. L. de; GUIMARÃES, R. J.; DIAS, F. P.; MOURA, C. A. Produção de mudas de cafeeiro enxertados. Lavras: UFLA, 2002. Não paginado. (Boletim de extensão).

TOMAZ, M. A.; SAKIYAMA, N. S.; MARTINEZ, H. E. P.; CRUZ, C. D.; PEREIRA, A. A.; FREITAS, R. S. de. Portaenxertos afetando o desenvolvimento de mudas de Coffea arabica L. Ciência Rural, Santa Maria, v. 35, n. 3, p. 570575, maio/jun. 2005. 